\title{
A Critical Approach on Using Total Water Footprint of Agricultural Products as a Potential Sustainable Development Indicator
}

\author{
Jean Vasile ANDREI, Rodica-Manuela GOGONEA, Marian ZAHARIA, Aurelia PATRASCU, Aniela BĂLĂCESCU, \\ Raluca Georgiana LADARU
}

\begin{abstract}
Measuring sustainable development represents a fundamental issue which requires a complex approach in identifying relevant indicators to capture the global transformations of the contemporary economic paradigm, within the context of increasing globalization and of the integration of markets and economies. The recent evolutions of the environmenta lanalysis enforced total water footprint as a highly popular and core environmental performance indicator. The paper presents a critical approach on using total water footprint of agricultural products as a potential sustainable development indicator from the EU perspective, by applying a specific research method on clustering and concentration. The results prove that total water footprint of the agricultural products is highly country-specific dependent. The uneven distribution shown by grouping of countries and types of agricultural products consumption confirm this argument.
\end{abstract}

Keywords: agricultural products; ecologic footprint; Lorentz concentration curve; Shannon Entropy; sustainable development; territorial distribution; water footprint

\section{INTRODUCTION}

Achieving sustainable development represents a key issue in contemporary economies, which faces wideranging processes of globalization of production flows and accentuation of sustainability challenges ranging from ageing populations and high levels of unemployment to persistent droughts and limiting access to water resources.

During the last decade numerous indicators were developed in order to analyze the degree and trends in achieving sustainable development goals. In the context of recent global economic transformations and the ever increasing need to ensure the sustainability of production systems, water footprint could be considered one of the most relevant and versatile indicators in highlighting the sustainability of agricultural system development, by providing significant elements in designing and implementation of the policy options identified by using water consumption.

As it has already been argued in literature [1,2], water is a core-element of human well-being, indispensable to life, which provides the necessary premises for achieving sustainable economic growth and for promoting a healthy ecosystem, favorable to inclusive development. Although there have been previous studies on the water footprint issue in literature [3-6], this study brings into discussion new approaches and perspectives by providing an overview and detailed images of the degree of distribution and concentration on water footprint of per capita national consumption of agricultural products. This research is considering all three types of the water footprint (Green, Blue and Grey), and it is grouped in two categories: internal and external. The application of numerical (concentration indicators) and graphical procedures (Lorentz concentration curves) adds value to the study by analyzing grouping, hierarchy and distribution of the water footprint of per capita national consumption of agricultural products, carried out in EU countries.

The procedures may specify the location of each country in the EU territorial context concerning the terms of distribution water footprint of agricultural products national consumption per capita.
The water footprint could be considered a good economic ergometer, indicating the level of water consumption required to obtain a certain product or production whether it produces economic benefits or not, or is useful to the society or not.

The water footprint has represented a core indicator of numerous studies concerning both the European Union member states [7-10] and outside [11], [15], revealing its importance in understanding sustainable development evolution and constrains.

As in [16] at the EU level, the distribution per country of green water footprint of per capita national consumption of agricultural products for the internal category ranges from the minimum value of $34,5 \mathrm{~m}^{3} / \mathrm{yr} / \mathrm{cap}$ which belongs to Belgium to a maximum of $1547,2 \mathrm{~m}^{3} / \mathrm{yr} / \mathrm{cap}$ corresponding to Hungary, resulting in a low concentration (of $32,79 \%$ ). The same intensity of concentration is determined for the external category, but the difference of green water footprint of national consumption of agricultural products per capita, compared to the internal one, according to data presented is lower by 73,50 $\mathrm{m}^{3} / \mathrm{yr} / \mathrm{cap}$, oscillating between $161,5 \mathrm{~m}^{3} / \mathrm{yr} / \mathrm{cap}$ in Romania and $1600,7 \mathrm{~m}^{3} / \mathrm{yr} / \mathrm{cap}$ in Malta [16].

However, a similar concentration degree is noted in the case of grey water footprint per capita of agricultural products. Thus, for agricultural products, the water consumption by country led to a rather significant concentration of $35,55 \%$, the consumption oscillating between Malta with $7,00 \mathrm{~m}^{3} / \mathrm{yr} / \mathrm{cap}$ and Slovenia with $205,2 \mathrm{~m}^{3} / \mathrm{yr} /$ cap as presented in [16].

Blue is the type of water for which issues related to the process of increasing water productivity and saving it under intensive use raise problems at European level. Issues arise especially when blue water is in direct interdependence with soil and surface water reserves, which are exhaustible, thus affecting the environment and being directly involved in the sustainability process.

The highest degree of concentration of blue water footprint of per capita national consumption $(80,66 \%)$ is recorded for agricultural products, by the internal component, and the largest consumer is Cyprus with the value of $220,6 \mathrm{~m}^{3} / \mathrm{yr} / \mathrm{cap}$ according to [16]. 
The explanation is primarily concerned with the unfavorable climatic conditions of this country (drought), the water demand for each crop production unit being very high. At the same time, the relief and soil types, as well as the problems related to the lack of efficient technologies, has led to low productivity. It is possible to add consumer attitudes, i.e., the population follows a model of intensive consumption of water through consumed agricultural products and especially meat products (the meat being the product consuming the largest quantities of water both for its production and processing).

The demand for water per product in agriculture concerns both vegetable and animal products. The values take into consideration all the water volume registered at the national level, both from natural process and from irrigation (without losses) and retained in the soil, needed for plant production.

The aim of the research was to highlight the interdependencies of the EU member states regarding the management of the water resources used in agriculture. Therefore, this paper focuses on the footprint of consumption of agricultural products at national level in the initial EU-28 countries and on the possibility to be considered as a potential sustainable development indicator.

\section{RESEARCH METHODOLOGY}

This study is based on a series of data published by UNESCO-IHE, Institute for Water Education, in 2011, in "Value of Water Research Report Series No. 50" [16], "Appendix VIII. The water footprint of per capita national consumption has been shown by major consumption category and by internal and external component $\left(\mathrm{m}^{3} / \mathrm{yr} / \mathrm{cap}\right) "$ where the results of the estimations are available both as a whole and by sectors: agricultural production, industrial production and domestic water use. Water footprint of consumption of agricultural products at national level (WFA) is the sum of two components: a direct component of intern water consumption, of the country's resources (internal water footprint of consumption of agricultural products - IWFA).

The second component is the indirect one (external water footprint of consumption of agricultural products EWFA) that represents the quantity of water used by other countries, for the production of agricultural products consumed by the consumers of the country under analysis.

Each of the components (IWFA and EWFA) is formed by three types of consumed water for the production of agricultural products: green water (water that comes from precipitations), blue water (water from underground or surface resources) and grey water (the quantity of fresh water needed to assimilate pollutants for the purposes of compliance with the specific water quality standards).

The series of data were organized in six vectors (three for the internal and three for the external components) as follows [17]:

$$
\boldsymbol{W}=\left[w_{i}\right]_{i=\overline{1,28}}
$$

Evaluation of the degree of concentration for water footprint of national consumption per capita $\left(\mathrm{m}^{3} / \mathrm{yr} / \mathrm{cap}\right)$ shown by major consumption category and by internal and external component at the level of EU countries, was analyzed both by applying graphical procedures (Lorentz curve), and by numerical procedures. The graphical process consists in building a polygonal curve obtained from the vector (1), indexed in increasing order $\left(w_{i} \leq w_{i+1}\right)$, by connecting the points $\left(x_{i}, y_{i}\right)_{i=0,28}$ where [17-18]:

$\left(x_{i}, y_{i}\right)=\left\{\begin{array}{l}(x=0, y=0), i=0 \\ \left(x_{i}=\frac{i}{28}, y_{i}=\frac{S_{i}}{S_{n}}\right), S_{i}=\sum_{j=1}^{i} w_{j}, i=\overline{1,28}\end{array}\right.$

The numerical indicators used [17] are Gini Coefficient (GC) and Shannon Entropy (SE):

$$
\begin{aligned}
& G C=\sqrt{\sum_{i=1}^{n} g_{i}^{2}}, \quad g_{i}=\frac{x_{i}}{\sum_{i=1}^{n} x_{i}}, \quad G C \in\left[\sqrt{\frac{1}{n}}, 1\right] \\
& S E=\sum_{i=1}^{n} g_{i} \cdot \ln \frac{1}{g_{i}}, \quad S E \in[1, \ln n]
\end{aligned}
$$

In relation to (3) $g_{i}$ is the share of water footprint from each territorial unit component analyzed in the cumulative value calculated at the level of the EU-28countries.

Under $G C \in([0,189 ; 1])$ and $S E \in(1 ; 3,332)$, the higher concentration of $G C$ is registered closer to the maximum limit of the value range dispartion. In the case of $S E$, the values are closer to the minimum limit of its range.

At the same time with analyzing the values of $G C$ and $S E$ coefficients, as well as with taking into account the shape of the Lorentz curve, for each of the six categories of analyzed water, and also taking into account the minimum values $w_{\min }=\min _{i=1,28} w_{i}$ and maximum $w_{\max }=\max _{i=1,28} w_{i}$, six intervals for the values $\left(G_{j}\right)$ with equal $(\Delta)$ amplitudes have been generated [17-18]:

$G_{j}=\left(L_{j}, U_{j}\right) ;\left\{\begin{array}{l}L_{j}=w_{\min }+(j-1) \cdot \Delta \\ U_{j}=L_{j}+\Delta\end{array}, \Delta=\frac{w_{\max }-w_{\min }}{6}, j=\overline{1,6}(4)\right.$

Taking into consideration the $G_{j}$ values dispersion, the concentration of a water footprint type of agricultural products will be as weaker as the cardinals of countries included in the designated value interval. In this case, it will tend towards equality.

On the contrary, the concentration will be as stronger as the cardinals of the respective sets will differ significantly. In this case, there may be one or more wide clusters (value ranges in which no country can be included).

The final part of the paper presents the results of a cluster analysis of the distribution of the $28 \mathrm{EU}$ countries according to all six indicators defining the water footprint of the agricultural product category. For this purpose, starting from the vectors $\boldsymbol{W}_{k}, k=\overline{1,6}$ corresponding to the six indicators analyzed above, the following matrix was constructed [17-18]: 


$$
\boldsymbol{X}=\left\|x_{i j}\right\|_{\substack{i=\overline{1,6} \\ j=1,28}}
$$

In order to determine the distance between the elements of the matrix $\boldsymbol{X}$ the Euclidian distance was used [17-18]:

$d_{i j}=\sqrt{\sum_{k=1}^{6}\left(w_{k i}-w_{k j}\right)^{2}}$

and for the distance between two clusters Average linkage between groups $(D G)$. Be it $\Phi$ and $\Psi$ two clusters with $N_{\Phi}$ and $N_{\Psi}$ elements [18], in this case, $D G$ is:

$D G(\Phi, \Psi)=\frac{1}{N_{\Phi} \cdot N_{\Psi}} \sum_{x \in \Phi} \sum_{y \in \Psi} d_{x y}$

Testing the statistical significance of the average variables analyzed, recorded at the level of clusters was performed with Welch's test for mean [19]. Confidence level $95 \%(\alpha=0,05)$ was used.

\section{RESULTS AND DISCUSSION}

The analysis of the concentration degree of the water footprint of per capita national consumption of agricultural products, at the level of EU countries, is split into three types (green, blue, grey) considering the two components: the internal and the external one.Through its content, the green water footprint of per capita consumption is only found in the case of agricultural products, for both internal and external components. The distribution of the green water footprint of consumption of agricultural products per country, evaluated in its two components (internal and external) is fairly uniform and similar (Fig. 1 (a) and Fig. 1 (b)), each curve being quite close to the diagonal of the square.

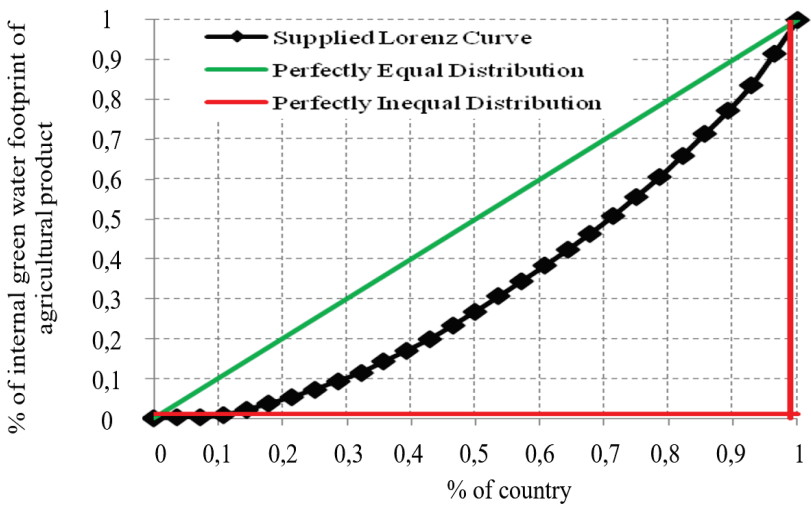

Figure 1 (a) The concentration curve of the internal green water footprint of consumption of agricultural products for groups of countries, Source: authors own computations based on [16]

Both the internal component and the external one, the low degree of concentration of the EU countries, for the water footprint green of consumption of agricultural products, is highlighted by the close results of the determined concentration indicators: the Gini Coefficient $(G C)$ and the Shannon Entropy $(S E)$.
The Shannon Entropy indicator, with the maximum values of 3,14 (internal) and 3,19 (external), close to the upper limit of 3,332, indicates a fairly low concentration of the countries grouping, for the water footprint green of consumption of agricultural products. This conclusion is also confirmed by the results of the indicator Gini Coefficient of 0,33 for Internal and 0,30 for the External category, which are very close to the inferior limit of 0,189 .

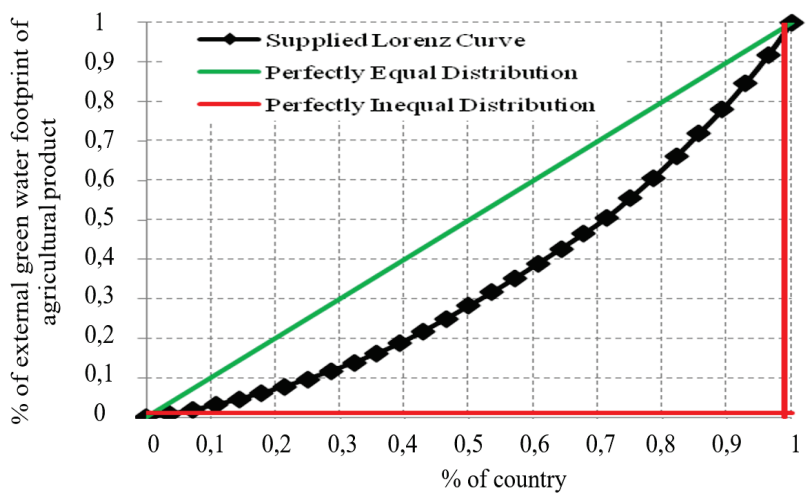

Figure 1 (b) The concentration curve of the external green water footprint of consumption of agricultural products for groups of countries, Source: authors own computations based on [16]

The country-specific natural conditions, the degree of their development, led to an uneven enough distribution of agricultural products for domestic use by group of countries, of the green water footprint of the consumption (Fig. 2). Thus, $17,86 \%$ of the total green water footprint of per capita consumption of agricultural products goes to $4,43 \%$ of countries including: Belgium, Netherlands, Malta, UK, and Ireland. For these countries, the green water footprint is the lowest, ranging from 34,5 to 286,64 $\mathrm{m}^{3} / \mathrm{yr} / \mathrm{cap}$. Of the total green water footprint, $42,86 \%$ is allocated to $20,83 \%$ of all countries. The established percentage is represented by the five countries in the first group, plus Germany, Cyprus, Slovenia, Austria, Luxembourg, Denmark, Sweden. In addition, 67,85\% of the total green water footprint of per capita consumption of agricultural products belongs to $46,08 \%$ of the countries (along with the 12 countries include Italy, Finland, Portugal, Slovakia, Estonia, France, Poland).
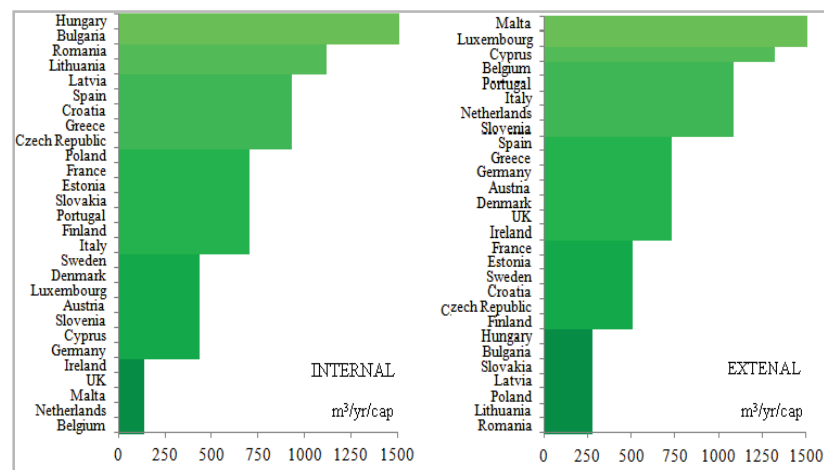

Figure 2 Distribution per groups of countries of the green water footprint of consumption of agricultural products, Source: authors' own design based on [16]

The level of the total green water footprint of agricultural products decreases form the referential of $85,71 \%$ to $71,40 \%$ in case of Czech Rep., Greece, Croatia, Spain, Latvia, adding 19 countries in the previous groups. 
In the fifth group, $92,86 \%$ of the total green water footprint per capita consumption of agricultural products is concentrated in $84,31 \%$ of the countries (along with the other 24 EU countries there are included: Lithuania and Romania).

Bulgaria and Hungary complete the territorial distribution belonging to the last group, recording the highest values of 1478,9 and $1547,2 \mathrm{~m}^{3} / \mathrm{yr} /$ cap of the total green water footprint of agricultural products.

The water content of virtual agricultural products varies from one country to another according to the relief, climate, technology adopted for agriculture, but also to the levels of yields obtained. Thus, on the external component, allocation of green water footprint of per capita consumption of agricultural products per countries, although different from the internal one, still maintains the direction of lack of uniformity.

Within this context, it is noted that the first group includes countries: Romania, Lithuania, Poland, Latvia, Slovakia, Bulgaria, and Hungary. They represent 10,03\% of the total number of countries and it receives $25,00 \%$ of the total green water footprint of per capita consumption of agricultural products. This group includes the countries with the lowest values of green water footprint of per capita consumption of agricultural products which oscillates between $161,5-401,39 \mathrm{~m}^{3} / \mathrm{yr} / \mathrm{cap}$ according to [16].

The countries of the first group join the components of the second group (Finland, Czech Republic, Croatia, Sweden, Estonia, and France) so that $25,97 \%$ of all countries will have $46,43 \%$ of the total green water footprint green of consumption of agricultural products. 7 other countries (Ireland, UK, Denmark, Austria, Germany, Greece and Spain) complete the first two groups, so that in the case of more than half of all countries $(53,10 \%)$ they have $71,43 \%$ of the total green water footprint of per capita consumption of agricultural products. Next, at the level of the fourth group, the 20 countries together with Slovenia, Netherlands, Italy, Portugal, Belgium, will form $78,60 \%$ of their total, comprising $89,29 \%$ of the total green water footprint of per capita consumption of agricultural products. An allocation of $84,92 \%$ of the total green water footprint of per capita consumption of agricultural products which belongs to $92,86 \%$ of all countries UE is established in the case of the fifth group (to the 25 countries only Cyprus being added).

The two countries of the last group, Luxembourg and Malta, are the largest green water footprints of consumption of agricultural products (1432,2 and 1600,7 $\mathrm{m}^{3} / \mathrm{yr} /$ cap [16]) thus completing the distribution of the green water footprint of per capita consumption of agricultural products at the level of all European countries.

A further argument in the sense outlined above is provided by the distribution of the Scatter plots (Fig. 3) which also highlights the distances between the green water consumption in the EU countries. In this regard, the distances are presented among the EU countries, which are big consumers of green water footprint of consumption of agricultural products (Hungary for internal and Malta for external, and the closest five countries to the above mentioned ones.

Considering that the use of blue water affects much more the natural environment than the use of green water, this study has also pursued an analysis of blue water footprint of per capita consumption of agricultural products at the level of EU countries.

Thus, national plans regarding water consumption have included estimates or quantifications of consumption of blue water footprint of per capita consumption of agricultural products shown by major consumption category and by the internal and external component.

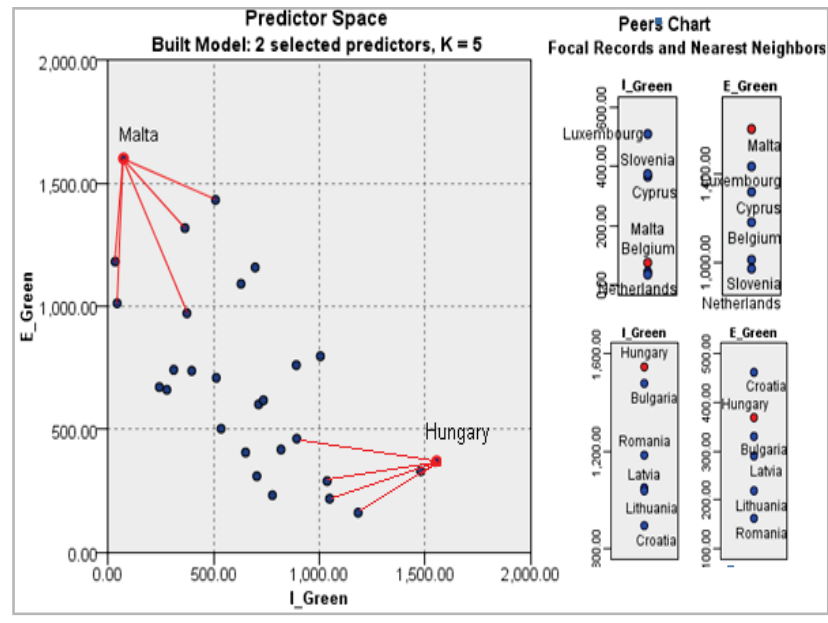

Figure 3 The Scatter plots of water footprint of consumption of agricultural products, Source: authors' own computations based on [16]

No matter whether it is water that comes from surface or underground water resources, evaporated, incorporated into a product, or taken from a water source that makes the water circuit in nature, it is distributed differently across countries within the EU. The justification is primarily concerned with the conditions of relief and implicitly soil, climate, which correspond to each country within the EU. Thus, the natural environment has an important contribution to the distribution of consumption of blue water, so a blue water footprint of consumption nationally (internal).

These distributions, differing significantly from one country to another on blue internal water footprint of per capita consumption, are mostly observed at the level of agricultural products. Agriculture, as the area most directly dependent on biotic and non-biotic environmental factors, has the most unequal territorial distribution of blue water footprint of per capita consumption in EU countries.

Confirmation is rendered by the low indicator value Entropy of only 1,93 compared to the lower limit 1 . The rather high concentration that is shown in the EU countries is also argued by Gini Coefficient, by the high value of 0,81 close to the upper limit 1.

Lorentz concentration curve of EU countries according to blue water footprint of per capita national consumption, agricultural products of consumption of Internal (Fig. 4 (a)) indicates a non-uniform territorial distribution of countries (the curve being very distant from the diagonal of the square).

Focused concentration of internal blue water footprint of per capita national consumption of agricultural products is given by 23 EU countries (Luxembourg, Ireland, Belgium, Latvia, Estonia, Lithuania, Slovenia, Croatia, UK, Czech Republic, Germany, Finland, Sweden, Poland, Austria, Netherlands, Denmark, Hungary, Bulgaria, Malta, Slovakia, France, Romania) which have natural conditions 
that have allowed them to consume such water between $0,00-36,78 \mathrm{~m}^{3} / \mathrm{yr} / \mathrm{cap}$.

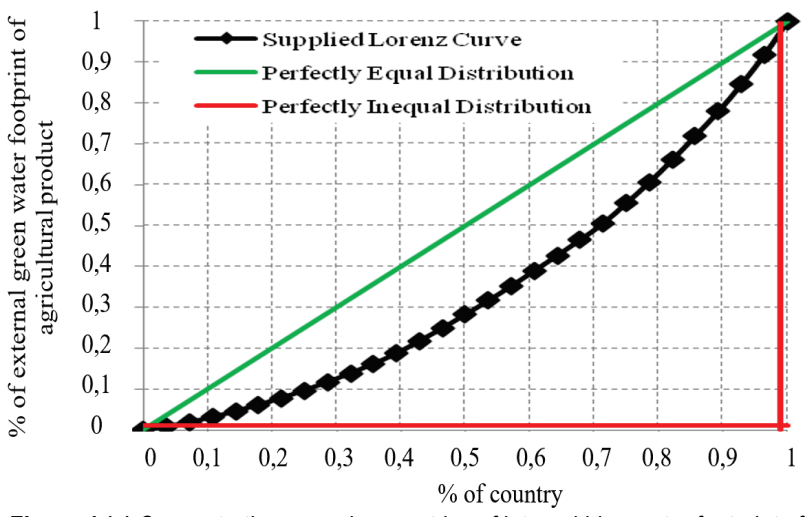

Figure 4 (a) Concentration curve by countries of internal blue water footprint of consumption of agricultural products, Source: authors' own computations based on [16]

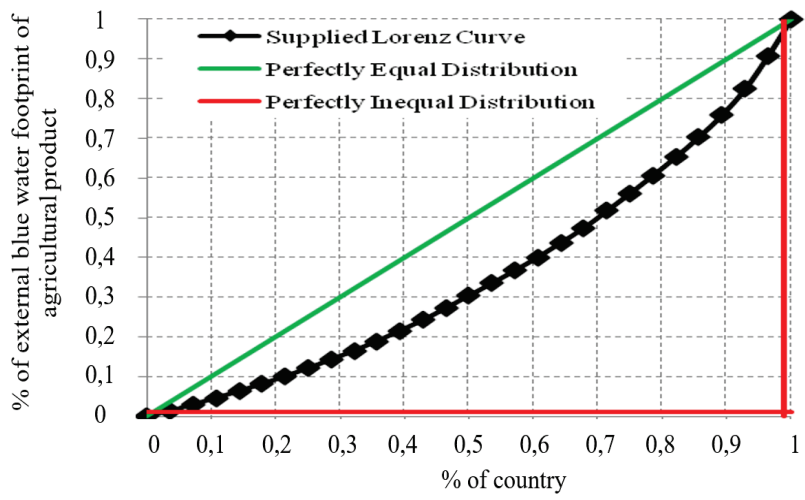

Figure 4 (b) Concentration curve by countries of external blue water footprint of consumption of agricultural products, Source: authors' own computations based on [16]

There are five countries diverging due to the high consumption of blue internal water. The only country with a consumption close to other 23 EU countries (36,78 $\left.73,54 \mathrm{~m}^{3} / \mathrm{yr} / \mathrm{cap}[16]\right)$ is Italy. In case of Portugal there is a consumption between 110,31-147,07 $\mathrm{m}^{3} / \mathrm{yr} / \mathrm{cap}[16]$.

Greece, Spain, Cyprus are countries that, due to environmental conditions and the behavioral pattern of the population (a model of intensive water consumption through consumed agricultural products that are high in water consumption), have come to their own blue internal water footprint of per capita national consumption. In case of agricultural products the values range between 183,84 $220,60 \mathrm{~m}^{3} / \mathrm{yr} / \mathrm{cap}$ as in [16].

The analysis of the blue water also considers the significant flow of virtual water between nations, from one exporting country to one importing country, as a result of the process of marketing their goods. Therefore, it is necessary to complete the study of blue water footprint of per capita consumption of agricultural products at the level of EU countries with the component external.

Many countries outsource a significant amount of blue water, because for governments, the development policy is considering a certain tendency to ensure national food security and raise the standard of living. These trends require a quantification of external blue water footprint of consumption of per capita agricultural products.

In the process of quantification of territorial concentration in EU countries, an external blue water footprint of per capita consumption for agricultural products represents the peculiarity of the significant difference between the recorded data.

In the major consumer category of agricultural products, Malta and Portugal are the two countries with the highest consumption of external blue water comprising between 168,85-196,90 $\mathrm{m}^{3} / \mathrm{yr} / \mathrm{cap}$. A significant gap $(37,4$ $\mathrm{m}^{3} / \mathrm{yr} / \mathrm{cap}$ ) appears between these two countries and the other 26 countries with the external blue water footprint of per capita consumption between 28,6 and $139 \mathrm{~m}^{3} / \mathrm{yr} / \mathrm{cap}$.

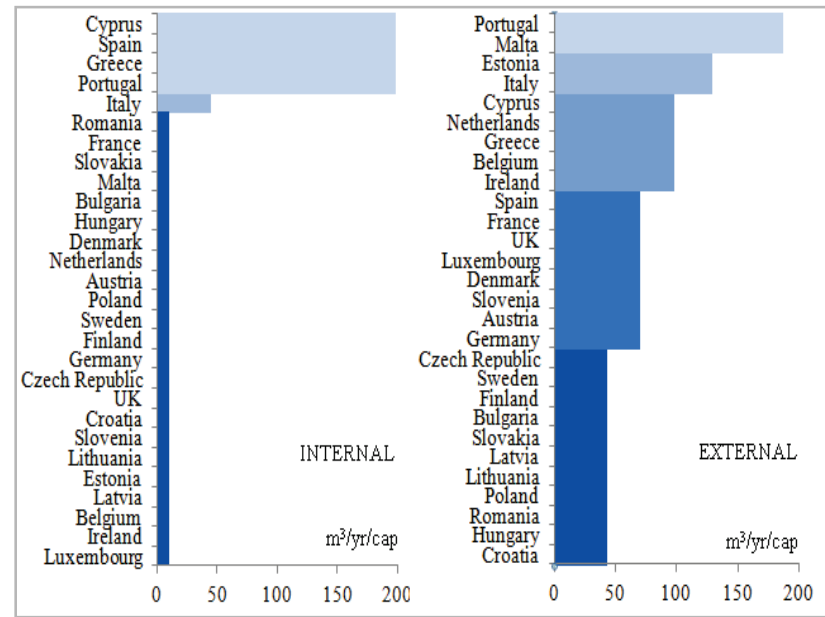

Figure 5 Distribution of blue water footprint of consumption of agricultural products by group of countries, Source: authors ' own design based on [16]

On the whole, since the concentration trend is given by most countries, it is noted that blue water footprint external of per capita consumption of agricultural products has a very low degree of concentration (Fig. 5).

Concentration indicators calculated for blue water footprint of agricultural products have great value for Entropy (approximate 3,2), which tends to the upper limit of 3,332, and Gini Coefficient with 0,28, which approaches the lower one of 0,189 , indicating a low concentration of blue water footprint external of per capita consumption of agricultural products. This aspect is also reflected by the Lorentz concentration curve (Fig. 4 (a)).

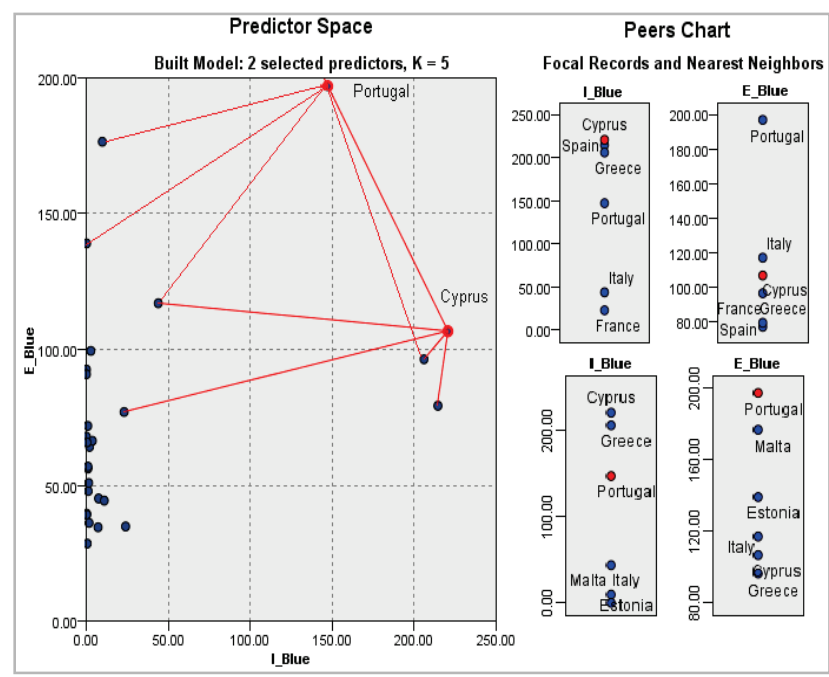

Figure 6 Scatter plots of blue water footprint of consumption of agricultural products, Source: authors' own computations based on [16] 
Most countries (Croatia, Hungary, Romania, Poland, Lithuania, Latvia, Slovakia, Bulgaria, Finland, Sweden, and Czech Republic) have a volume of external blue water footprint of per capita consumption of agricultural products comprising between $28,6-56,62 \mathrm{~m}^{3} / \mathrm{yr} /$ cap according to [16].

The next group includes eight countries (Germany, Austria, Slovenia, Denmark, Luxembourg, UK, France, and Spain) whose consumption of blue water footprint external of agricultural products oscillates between 56,62 84,67 $\mathrm{m}^{3} / \mathrm{yr} / \mathrm{cap}$ [16]. Ireland, Belgium, Greece, Netherlands, Cyprus are the countries that form a group with external blue water footprint of per capita consumption of agricultural products comprising between $84,67-112,73 \mathrm{~m}^{3} / \mathrm{yr} / \mathrm{cap}$ [16]. If Italy and Estonia are the countries with consumption of external blue water footprint of agricultural products of 112,73 - 140,79 $\mathrm{m}^{3} / \mathrm{yr} / \mathrm{cap}$ for Malta, Portugal this consumption is between $168,85-196,90 \mathrm{~m}^{3} / \mathrm{yr} / \mathrm{cap}$.

The two-dimensional representation (Fig. 6) highlights the fact that out of the 28 EU countries, 23 countries are concentrated on low consumption (between 0 and 37 $\mathrm{m}^{3} / \mathrm{yr} / \mathrm{cap}$ internally, respectively between 29 and 113 $\mathrm{m}^{3} / \mathrm{yr} /$ cap externally [16]), and five are dispersed (Italy, Portugal, Greece, Spain and Cyprus). Of these, Portugal and Cyprus are positioned far from other countries due to their very high level of external blue water footprint of per capita consumption of agricultural products.

The water footprint is also closely related to the third constituent element: grey water footprint, analyzed by the internal and the external component in turns. At the same time, the importance of this type of water can be highlighted mainly by transposing the measured effect into agricultural products.

At the level of the EU countries, the concentration indicators highlighted the existence of a low degree of concentration, with an average trend, for grey water footprint on the internal component of agricultural products. This is evidenced by the values of the Shannon indicator Entropy of 3,12 for internal and 3,21 for external water footprint, close to the upper limit of 3,332 and those of the Gini Coefficient of 0,36 (internal) and 0,28 (external), with values pointing to 0,189 . This trend is also evidenced by the Lorentz Curves (Fig. 7 (a) and Fig. 7 (b)). The variation of this indicator is significantly influenced by the level of pollution recorded in each country and its ability to decrease its harmful effects. So at the level of the 28 EU countries, the distribution on grey internal water footprint of per capita consumption is between 7,0 and $205,17 \mathrm{~m}^{3} / \mathrm{yr} /$ cap by groups.

The analysis highlights that out of the total grey internal water footprint of per capita consumption of agricultural products 6,93\% countries: Malta, Belgium, Netherlands, Finland, Cyprus, Lithuania, Ireland whose footprints of grey water oscillate between 7,0 and 40,04 $\mathrm{m}^{3} / \mathrm{yr} / \mathrm{cap}$; those are the countries which hadve succeeded to control the water pollution degree in the best way to obtain agricultural products.

The second group adds 5 countries to the previous ones (Austria, UK, Romania, Portugal, France) for which internal grey water footprint of per capita consumption of agricultural products represents $18,83 \%$ of the total, the variation range of the grey water footprint being between
40,04 - 73,06 $\mathrm{m}^{3} / \mathrm{yr} / \mathrm{cap}$ as in [16]. Countries: Denmark, Slovakia, Estonia, Sweden, Germany, Greece, Italy and Luxembourg are the components of the third group (the grey water mark fluctuates between 73,06 - 106,09 $\left.\mathrm{m}^{3} / \mathrm{yr} / \mathrm{cap}[16]\right)$ which, together with the other 12 , include $48,99 \%$ of total internal grey water footprint of per capita consumption of agricultural products.

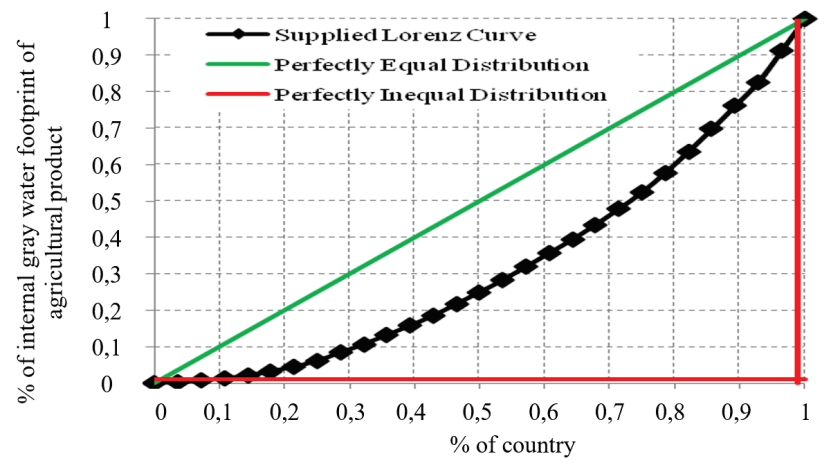

Figure 7 (a) Concentration curve on internal grey water footprint of consumption of agricultural products by countries, Source: authors ' own computations based on [16]

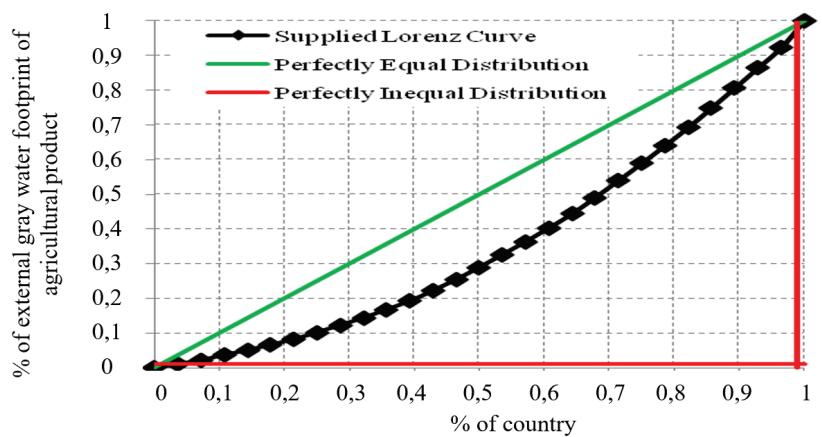

Figure 7 (b) Concentration curve on external grey water footprint of consumption of agricultural products by countries, Source: authors 'own computations based on [16]

Grey water footprint between 106,09 - 139,11 $\mathrm{m}^{3} / \mathrm{yr} /$ cap [16] is found for Latvia, Bulgaria, Croatia; added to the previous ones, out of the total grey water footprint internal of per capita consumption of agricultural products a water footprint of $64,47 \%$ will be determined. With a high degree of water pollution used for agricultural products at national level, Spain, Czech Republic, Poland (with Grey water variation between 139,11 - 172,14 $\mathrm{m}^{3} / \mathrm{yr}$ /cap [16]) are three countries that complement the range of others included in the analysis, setting across the territory of the EU an internal grey water footprint of per capita consumption of agricultural products of $84,12 \%$ of the total. Hungary and Slovenia are the components of the last group $\left(172,14\right.$ - 205,17 $\mathrm{m}^{3} / \mathrm{yr} / \mathrm{cap}$ [16]) which complete the distribution of internal grey water footprint of per capita consumption of agricultural products. Of these, Slovenia is at the farthest distance from the others (Fig. 8).

Most countries (Romania, Bulgaria, Poland, Latvia, Hungary, Lithuania, Slovakia, France, Estonia) representing $14,32 \%$ of the total number under analysis are included in the first group (Fig. 8) with the lowest volume of per capita consumption of $32,14 \%$ of the total grey water footprint external of agricultural products.

The second and fifth groups include four constituent countries (Finland, Czech Republic, Croatia, Sweden, 
respectively Slovenia, Portugal, Cyprus, Belgium), and include $14,29 \%$ of the total external grey water footprint of agricultural products, although the volume of water varies from one group to another.
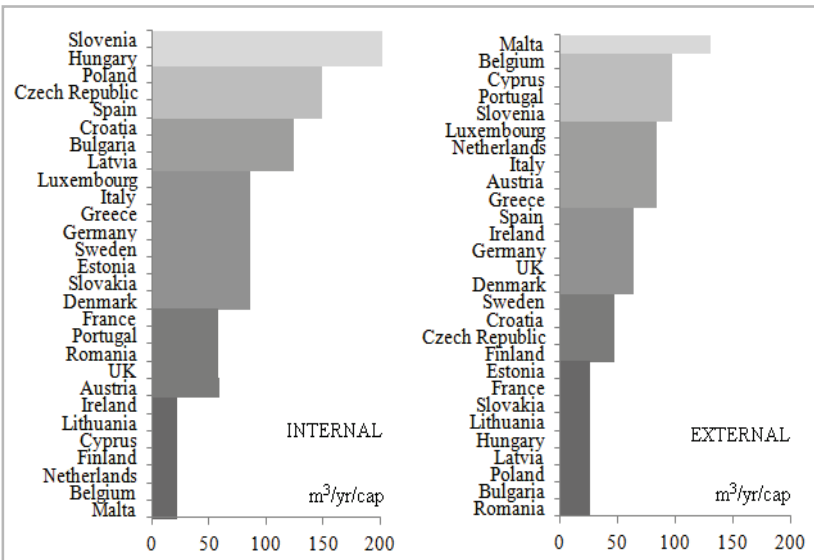

Figure 8 Distribution by countries of grey water footprint of consumption of agricultural products, Source: authors' own design based on [16]

The same situation is also noted in the third and fourth groups. Thus, the five constituent countries of each group (Denmark, UK, Germany, Ireland, Spain, respectively Greece, Austria, Italy, Netherlands, Luxembourg), although there is a different water volume from one group to another, still account for a share of $17,86 \%$ of the total external grey water footprint of agricultural products.

Through a separate group, Malta joins the 27 countries with $96,43 \%$ of total external grey water footprint of agricultural products (Fig. 9). This is the country with a significant difference of $32,63 \mathrm{~m}^{3} / \mathrm{yr} / \mathrm{cap}$ of the consumption of external grey water footprint of agricultural products compared to Belgium ranked last in the fifth group.
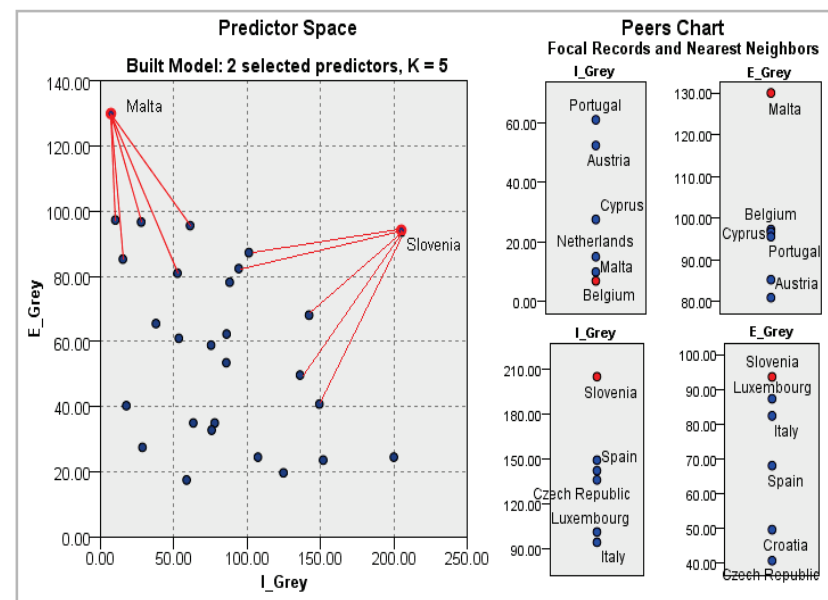

Figure 9 Scatter plots of grey water footprint of consumption of agricultural products, Source: authors' own computations based on [16]

In order to have the most complete picture on the distribution of water footprint of agricultural product in EU countries, a cluster analysis including all six indicators analyzed above (I_Green, I_Blue, I_Grey, E_Green, E_Blue and E_Grey) has been used. For obtaining the proximity matrix and to generate the clusters, the Euclidean distance and respectively the average linkage between groups have been used.
Following the analysis, we have opted for a grouping in six clusters. Testing the statistical significance of the averages of the variables analyzed with Welch Robust Tests of Equality of Means (Tab. 1) highlights that for the variable I_Grey, Sig. $=0,683>\alpha=0,05$ the null hypothesis is accepted: the averages determined at cluster level are not statistically significant. Consequently, it was excluded from the analysis.

Table 1 Results of Welch Robust Tests of Equality of Means for grouping in six clusters according to all six variables included in the analysis, Source: authors

\begin{tabular}{|l|c|c|c|c|}
\hline \multirow{2}{*}{ Type of water } & $\begin{array}{c}\text { Welch } \\
\text { Statistic }^{\mathrm{a}}\end{array}$ & \multicolumn{2}{|c|}{ degrees of freedom } & \multirow{2}{*}{ Sig. } \\
\cline { 3 - 4 } & 22,261 & 4 & $d f 2$ & \\
\hline I_Green & 423,920 & 4 & 6.377 & 0,001 \\
\hline I_Blue & 0,590 & 4 & 5.988 & 0,683 \\
\hline I_Grey & 45,848 & 4 & 9.445 & 0,000 \\
\hline E_Green & 13,155 & 4 & 5.293 & 0,006 \\
\hline E_Blue & 72,801 & 4 & 5.796 & 0,000 \\
\hline E_Grey & \multicolumn{4}{l}{} \\
\hline a. Asymptotically F distributed.
\end{tabular}

The resuming of the cluster analysis, this time from the other five indicators (I_Green, I_Blue, E_Green, E_Blue and E_Grey), revealed the statistical significance of the averages of all five variables recorded at cluster level (Tab. 2).

Table 2 Results of Welch Robust Tests of Equality of Means for clustering in six clusters after excluding the I_Grey variable, Source: authors' own computations \begin{tabular}{|l|l|l|l|}
\hline Type of water & WelchStatistic $^{\mathrm{a}}$ & degrees of freedom & Sig.
\end{tabular}

\begin{tabular}{|l|l|l|l|l|} 
Type of water & \multirow{2}{*}{ WelchStatistic } & \multicolumn{2}{|c|}{ degrees of freedom } & \multirow{2}{*}{ Sig. } \\
\cline { 3 - 4 } & & $d f 1$ & $d f 2$ & \\
\hline I_Green & 77,152 & 4 & 5,468 & 0,000 \\
\hline I_Blue & 439,206 & 4 & 5,137 & 0,000 \\
\hline E_Green & 71,002 & 4 & 6,804 & 0,000 \\
\hline E_Blue & 6,891 & 4 & 5,071 & 0,028 \\
\hline E_Grey & 60,609 & 4 & 5,118 & 0,000 \\
\hline a. Asymptotically F distributed.
\end{tabular}

Under these circumstances, the allocation of countries in clusters is rather uneven (Tab. 3). Regarding this group, it is worth noting that due to its peculiarities in terms of water footprint of agricultural products, Malta could not be included in one of the other clusters and it is highlighted separately (a "single" grouping).

Table 3. Grouping of EU states in clusters using Euclidian distance and average linkage between groups depending on the values of the variables I_Green,

I_Blue, E_Green, E_Blue and E_Grey, Source: authors' own design based on

\begin{tabular}{|l|l|}
\hline Cluster & Countries included [16] \\
\hline C1 & $\begin{array}{l}\text { Austria, Belgium, Denmark, Germany, Ireland, } \\
\text { Netherlands, Slovenia, UK }\end{array}$ \\
\hline C2 & Bulgaria, Hungary, \\
\hline C3 & $\begin{array}{l}\text { Croatia, Czech Republic, Estonia, Finland, France, Latvia, } \\
\text { Lithuania, Poland, Romania, Slovakia, Sweden }\end{array}$ \\
\hline C4 & Cyprus, Italy, Portugal, Luxemburg \\
\hline C5 & Greece, Spain \\
\hline C6 & Malta \\
\hline
\end{tabular}

The main characteristics of the clusters are highlighted and can be analyzed by means of the average consumption at each level (Tab. 4).

The analysis performed at the level of the clusters, in relation with the five indicators presented, considers their classification starting from the first stage with the lowest average consumption water footprint of agricultural products, to the largest, which corresponds to the last step (sixth). 
Table 4 Characteristics of clusters of countries included in clusters generated by the values of the five water footprint indicators included in the analysis, Source: authors' own computations based on [16]

\begin{tabular}{|c|c|c|c|c|c|c|}
\hline \multirow{2}{*}{ Cluster } & \multirow{2}{*}{$\begin{array}{c}\text { Number } \\
\text { of } \\
\text { countries }\end{array}$} & \multicolumn{5}{|c|}{ Water footprint of agricultural products $\mathrm{m}^{3} / \mathrm{yr} / \mathrm{cap}$} \\
\hline & & I_Green & I_Blue & E_Green & E_Blue & E_Grey \\
\hline $\mathrm{C} 1$ & 8 & 274,32 & 1,39 & 835,94 & 76,03 & 75,61 \\
\hline $\mathrm{C} 2$ & 2 & 1513,05 & 7,35 & 349,75 & 39,90 & 22,10 \\
\hline $\mathrm{C} 3$ & 11 & 826,91 & 5,89 & 383,79 & 53,99 & 34,56 \\
\hline $\mathrm{C} 4$ & 4 & 549,72 & 102,92 & 1249,80 & 122,15 & 90,50 \\
\hline C5 & 2 & 947,90 & 210,25 & 779,20 & 87,85 & 73,15 \\
\hline C6 & 1 & 74,13 & 9,83 & 1600,72 & 176,37 & 129,95 \\
\hline
\end{tabular}

Cluster 1 (C1) and third (C3) include most countries (8 countries the first and 11 the other) for which average consumption water footprint of agricultural products is quite low. Thus, compared to the other cluster countries, $\mathrm{Cl}$ cluster (Austria, Belgium, Denmark, Germany, Ireland, Netherlands, Slovenia, UK) has the lowest consumption water footprint of agricultural products la I_Blue of 1,39 $\mathrm{m}^{3} / \mathrm{yr} / \mathrm{cap}$, occupying the first place in this type of water and this category and the second place at I_Green with $274,32 \mathrm{~m}^{3} / \mathrm{yr} / \mathrm{cap}$.

For the external category, for the blue water type, $\mathrm{C} 1$ is ranked third compared to the others $\left(76,03 \mathrm{~m}^{3} / \mathrm{yr} / \mathrm{cap}\right.$ based on [16]) while the fourth place is occupied by this cluster for both E_Green and E_Grey with 835,94 $\mathrm{m}^{3} / \mathrm{yr} / \mathrm{cap}$, respectively with $75,61 \mathrm{~m}^{\overline{3}} / \mathrm{yr} / \mathrm{cap}$.

This low consumption of water footprint of agricultural products is highlighted in the third cluster countries (Croatia, Czech Republic, Estonia, Finland, France, Latvia, Lithuania, Poland, Romania, Slovakia, Sweden) both by the mean values determined and by the second place in the rankings of clusters occupied by cluster two (C2) in almost all categories and types of water included in the analysis: I Blue with $5,89 \mathrm{~m}^{3} / \mathrm{yr} / \mathrm{cap}$, E_Green with $383,79 \mathrm{~m} 3 / \mathrm{yr} / \mathrm{cap}$, E Blue with 53,99 $\mathrm{m} 3 / \mathrm{yr} / \mathrm{cap}$ and E_Grey with $34,5 \overline{6} \mathrm{~m}^{3} / \mathrm{yr} / \mathrm{cap}$. The exception is the I_Green category that places this cluster at the middle of the ranking (third place) by the mean value of the consumption water footprint of agricultural products of $826,91 \mathrm{~m}^{3} / \mathrm{yr} / \mathrm{cap}$.

First, with the lowest average consumption of water footprint of agricultural products are Bulgaria and Hungary, the components of cluster $\mathrm{C} 2(\mathrm{C} 2)$ in the external category, regarding all three types of water: $\mathrm{E}$ Green with $349,75 \mathrm{~m}^{3} / \mathrm{yr} / \mathrm{cap}$, E_Blue with $39,90 \mathrm{~m}^{3} / \mathrm{yr} / \mathrm{cap}$ and E_Grey with the value of $22,10 \mathrm{~m}^{3} / \mathrm{yr} / \mathrm{cap}$ [16]. With regard to the internal category, with $7,35 \mathrm{~m}^{3} / \mathrm{yr} / \mathrm{cap}, \mathrm{C} 2$ becomes the 3rd place holder for the water blue type and the highest average consumption is $1513,05 \mathrm{~m}^{3} / \mathrm{yr} / \mathrm{cap}$ [16], C2 will be in the last place, six, for green water footprint of agricultural products.

Four countries (Cyprus, Italy, Portugal, Luxemburg), components of cluster four (C4) have a high consumption of water footprint of agricultural products, confirmed by the penultimate place, five, occupied by it for four of the five indicators included in the analysis: I_Blue with 102,92 $\mathrm{m}^{3} / \mathrm{yr} / \mathrm{cap}$, E_Green with $1249,80 \mathrm{~m}^{3} / \mathrm{yr} / \mathrm{cap}$, E Blue with $122,15 \mathrm{~m}^{3} / \mathrm{yr} /$ cap and E_Grey with $90,50 \mathrm{~m}^{3} / \mathrm{yr} /$ cap. As with C3, I_Green is the only category that discovers the average water footprint of agricultural products of 549,72 $\mathrm{m}^{3} / \mathrm{yr} / \mathrm{cap}$, occupying the fourth position. Malta, the only component country of the sixth cluster (C6), has a similar situation to cluster $\mathrm{C} 2$ in the sense that in the external category, all types of water footprint of agricultural products cause it to occupy the same place in the classification.

The situation of this country, implicitly of this cluster, is opposite in the sense that, this time, C6 will be ranked last by the highest values of consumption water footprint of agricultural products: E_Green with $1600,72 \mathrm{~m}^{3} / \mathrm{yr} / \mathrm{cap}$, E_Blue with $176,37 \mathrm{~m}^{3} / \mathrm{yr} /$ cap and E_Grey with 129,95 $\mathrm{m}^{3} / \mathrm{yr} /$ cap. With only $74,13 \mathrm{~m}^{3} / \mathrm{yr} / \mathrm{cap}$ on green water for the internal component, as presented in [16], Malta is the country with the lowest water footprint of agricultural products, occupying the first place, while for I_Blue, 9,83 $\mathrm{m}^{3} / \mathrm{yr} /$ cap will be placed on the fourth place, as compared to the other clusters.

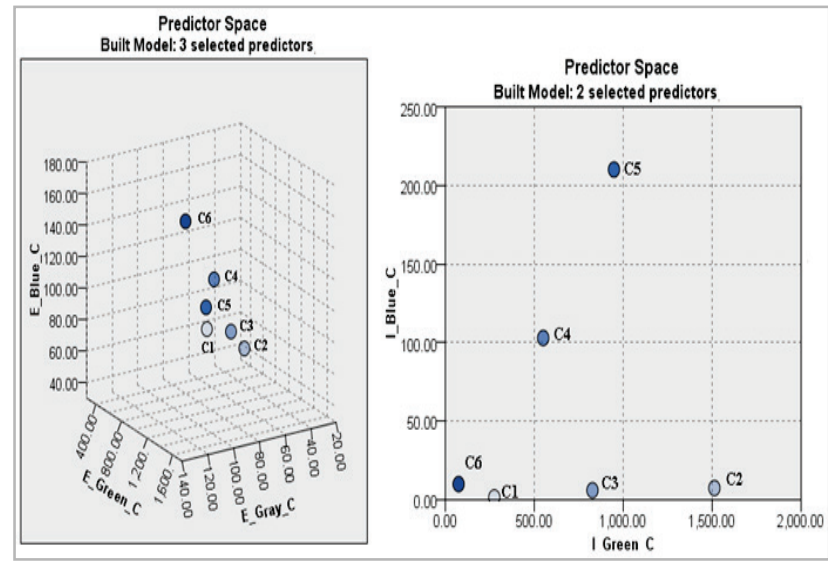

Figure 10 Scatter plots of average water footprint of consumption of agricultural products at the cluster level: external (left), internal (right), Source: authors' own computations based on [16]

The distribution of the average consumption of water footprint of agricultural products is also well reflected by the three-dimensional graphic representation (Fig. 10 - left) of the external component (E Green, E Blue, E_ Grey) and two-dimensional (I_Blue, I_Grey) by Fig. 10 - right). The figure of the distribution of water footprint of agricultural products on clusters brings to the forefront the need to apply strategically measures to reduce or increase consumption in line with the possibilities imposed by each category, type of water and each country in accordance with the characteristics, particularities and needs of each.

\section{CONCLUSIONS}

In conclusion, it can be stated that according to the degree of concentration of water footprint agricultural products are the same by water type (Green, Blue and Grey) and by internal and external component. So overall, at the EU level there is a balance in consumption. This result is beneficial in the sense that all EU countries can work together in the direction of water saving and its efficient use in the direction of sustainable development. The exception is only the case of internal blue water footprint for agricultural products for which countryspecific strategic measures are required. More favorable situations for the sustainability process are highlighted by the low concentration reported on the external component, for blue water footprint for agricultural products $(28,33 \%)$ and on grey water footprint agricultural products with $27,9 \%$. These results highlight that the exchange of 
products has been fairly balanced between countries in terms of blue and grey water footprints in their production.

The clustering process has brought extra information, reflecting the level of consumption concentration water footprint for agricultural products at the level of the groups of countries, by categories and types of water. Thus, I_Green has the lowest consumption level in Malta (C6) and the highest in Bulgaria and Hungary (C2), among them including clusters: $\mathrm{C} 1, \mathrm{C} 3, \mathrm{C} 4, \mathrm{C} 5$, in increasing order of consumption. Category I_Blue records the lowest consumption values in Cluster $\mathrm{C} 1$, followed by $\mathrm{C} 3$, then $\mathrm{C} 2$ and $\mathrm{C} 6$, so that the most significant values of average consumption are for countries in clusters C5 and C6. Our analysis is a stage of research done in order to better clarify the place and role of each country at the European level in terms of water footprint of consumption of agricultural products, highlighting their interdependence.

\section{REFERENCES}

[1] Vigerstol, K. L. \& Aukema, J. E. (2011). A comparison of tools for modeling freshwater ecosystem services. Journal of environmental management, 92(10), 2403-2409. https://doi.org/10.1016/j.jenvman.2011.06.040

[2] D'Ambrosio, E., De Girolamo, A. M., \& Rulli, M. C. (2018), Assessing sustainability of agriculture through water footprint analysis and in-stream monitoring activities. Journal of Cleaner Production, 200, 454-470. https://doi.org/10.1016/j.jclepro.2018.07.229

[3] Aivazidou, E., Tsolakis, N., Vlachos, D. P., \& Iakovou, E. (2017). Water footprint mitigation strategies for agrifood products: the application of system dynamics in green marketing. In Strategic Innovative Marketing, 275-281. Springer, Cham. https://doi.org/10.1007/978-3-319-33865-1_35

[4] Lovarelli, D., Ingrao, C., Fiala, M., \& Bacenetti, J. (2018). Beyond the Water Footprint: A new framework proposal to assess freshwater environmental impact and consumption. Journal of cleaner production, 172, 4189-4199. https://doi.org/10.1016/j.jclepro.2016.12.067

[5] Haie, N., Rodrigues, F., M., \& Castro Pereira, J. (2018) Integrating Water Footprint and Sefficiency: Overcoming Water Footprint Criticisms and Improving Decision Making. Water Alternatives, 11(3).

[6] Ercin, A. E. \& Hoekstra, A. Y. (2014). Water footprint scenarios for 2050: A global analysis. Environment international, 64, 71-82. https://doi.org/10.1016/j.envint.2013.11.019

[7] Yu, Y., Hubacek, K., Feng, K., \& Guan, D. (2010). Assessing regional and global water footprints for the UK. Ecological Economics, 69(5), 1140-1147. https://doi.org/10.1016/j.ecolecon.2009.12.008

[8] Vanham, D. \& Bidoglio, G. (2013). A review on the indicator water footprint for the EU28. Ecologicalindicators, 26, 61-75. https://doi.org/10.1016/j.ecolind.2012.10.021

[9] Hoekstra A. Y. \& Chapagain A. K. (2007) .Water footprints of nations: Water use by people as a function of their consumption pattern, Water Resour. Manage, 21, 35-48. https://doi.org/10.1007/s11269-006-9039-x

[10] Hoekstra, A. Y. (2009). Human appropriation of natural capital: A comparison of ecological footprint and water footprint analysis. Ecologicaleconomics, 68(7), 1963-1974. https://doi.org/10.1016/j.ecolecon.2008.06.021

[11] Tom, M. S., Fischbeck, P. S., \& Hendrickson, C. T. (2016). Energy use, blue water footprint, and greenhouse gas emissions for current food consumption patterns and dietary recommendations in the US. Environment Systems and Decisions, 36(1), 92-103. https://doi.org/10.1007/s10669-015-9577-y
[12] Ayala, L. M., van Eupen, M., Zhang, G., Pérez-Soba, M., Martorano, L. G., Lisboa, L. S., \& Beltrao, N. E. (2016). Impact of agricultural expansion on water footprint in the Amazon under climate change scenarios. Science ofthe Total Environment, 569, 1159-1173. https://doi.org/10.1016/j.scitotenv.2016.06.191

[13] Yoo, S. H., Lee, S. H., Choi, J. Y., \& Im, J. B. (2016). Estimation of potential water requirements using water footprint for the target of food self-sufficiency in South Korea. Paddy andwaterenvironment, 14(1), 259-269. https://doi.org/10.1007/s10333-015-0495-x

[14] Hubacek, K., Guan, D., Barrett, J., \& Wiedmann, T. (2009). Environmental implications of urbanization and lifestyle change in China: Ecological and water footprints. Journal of Cleaner Production, 17(14), 1241-1248. https://doi.org/10.1016/j.jclepro.2009.03.011

[15] Cohen, E. \& Ramaswami, A. (2014). The water withdrawal footprint of energy supply to cities: Conceptual development and application to Denver, Colorado, USA. Journal of Industrial Ecology, 18(1), 26-39. https://doi.org/10.1111/jiec.12086

[16] Mekonnen, M. M. \& Hoekstra, A. Y. (2011). National water footprint accounts: the green, blue and grey water footprint of production and consumption, Value of Water Research Report Series No. 50, UNESCO-IHE, Delft, the Netherlands. https://waterfootprint.org/media/downloads/Report50NationalWaterFootprints-Vol2.pdf

[17] Jaba， E. (2002). Statistica，ed. a 3-a, Ed. Economică, București. (in Romanian language)

[18] Rotaru, T., Badescu, G., Culic, I., Mezei, E., \& Mureșan, C. (2006). Metode statistice aplicate in științele sociale, Ed. Polirom, Iași. (in Romanian language)

[19] Field, A. P. (2009). Discovering statistics using SPSS, $3^{\text {rd }}$ edition. London.

\section{Contact information}

Jean Vasile ANDREI, prof. habil., PhD

(Corresponding author)

Faculty of Economic Sciences, Petroleum-Gas University of Ploiesti,

B-dul Bucuresti, No. 39, 100680, Ploiesti, Prahova, Romania

E-mail: andrei_jeanvasile@yahoo.com

Rodica-Manuela GOGONEA, Assoc. Prof., PhD

Faculty of Cibernetic Statistic and Economic Informatics,

The Bucharest University of Economic Studies,

15-17 Dorobanti St., Sector 1, 010552, Bucharest, Romania

E-mail: manuela.gogonea@gmail.com

Marian ZAHARIA, Prof. PhD

Faculty of Economic Sciences, Petroleum-Gas University of Ploiesti, B-dul Bucuresti, No.39, 100680, Ploiesti, Prahova, Romania

E-mail: marianzaharia53@gmail.com

\section{Aurelia PATRASCU, Assoc. Prof., PhD}

Faculty of Economic Sciences, Petroleum-Gas University of Ploiesti, B-dul Bucuresti, No.39, 100680, Ploiesti, Prahova, Romania

E-mail: patrascuaura@yahoo.com

\section{Aniela BĂLĂCESCU, Assoc. Prof., PhD}

Faculty of Economics, Constantin Brâncuși University of Targu Jiu, Postal address: No. 4, Tineretului Street, Târgu Jiu, Gorj County, Romania E-mail: anielabalacescu@yahoo.com

Raluca Georgiana LADARU, Assoc. Prof., PhD Faculty of Agrifood and Environmental Economics, The Bucharest University of Economic Studies

Mihail Moxa Street, no. 5-7, District 1, Bucharest 010374, Romania E-mail: graluca85@yahoo.com 